\title{
Do extended incubation recesses carry fitness costs in two cavity-nesting birds?
}

\author{
Javier Bueno-Enciso, ${ }^{1,5}$ Rafael Barrientos, ${ }^{1,2,3}$ Esperanza S. Ferrer, ${ }^{1}$ and \\ Juan José Sanz ${ }^{4}$
${ }^{1}$ Facultad de Ciencias del Medio Ambiente, Departamento de Ciencias Ambientales, Universidad de Castilla-La Mancha, Avenida Carlos III, s/n, E-45071, Toledo, Spain
${ }^{2}$ Infraestruturas de Portugal Biodiversity Chair, CIBIO - Research Center in Biodiversity and Genetic Resources, \\ Campus Agrário de Vairão, R. Padre Armando Quintas, 4485-661, Vairão, Portugal \\ ${ }^{3}$ CEABN/InBio, Centro de Ecologia Aplicada "Professor Baeta Neves", Instituto Superior de Agronomia, Universidade \\ de Lisboa, Tapada da Ajuda, 1349-017, Lisboa, Portugal \\ ${ }^{4}$ Departamento de Ecología Evolutiva, Museo Nacional de Ciencias Naturales (CSIC), Cl José Gutiérrez Abascal 2, \\ E-28006, Madrid, Spain
}

Received 1 August 2016; accepted 17 February 2017

\begin{abstract}
Because extended incubation recesses, where incubating songbirds are away from nests for periods much longer than usual, occur infrequently, they have been treated as outliers in most previous studies and thus overlooked. However, egg temperatures can potentially fall below the physiological zero temperature during extended recesses, potentially affecting developing embryos. As such, evaluating extended recesses in an ecological context and identifying their possible fitness effects are important. With this aim, we used iButton data loggers to monitor the incubation behavior of female Blue Tits (Cyanistes caeruleus) and Great Tits (Parus major) during two breeding seasons in central Spain. We classified incubation recesses as extended if they were more than four times the mean recess duration for each species. Extended incubation recesses occurred more frequently in 2012 when females exhibited poorer body condition. Female Blue Tits had more extended incubation recesses than female Great Tits and, for both species, more extended recesses occurred at the beginning of the breeding season. Both nest attentiveness and average minimum nest temperature decreased when at least one extended recess occurred. Incubation periods averaged $4 \mathrm{~d}$ longer for nests where females had at least one extended recess, potentially increasing predation risk and resulting in lower-quality nestlings. Overall, our results suggest that extended recesses may be more common among songbirds than previously thought and that, due to their effects on egg temperatures and attentiveness, they could impose fitness costs.
\end{abstract}

RESUMEN. ¿Tienen los recesos prolongados en la incubación costos en la aptitud en aves que anidan en cavidades?

Debido a que los periodos extendidos o prolongados de receso durante los cuales el ave que incuba se ausenta del nido por un periodo más largo de lo usual son poco frecuentes, éstos han sido tratados como atípicos o han sido ignorados. Sin embargo, la temperatura de los huevos puede disminuir muy por debajo de la temperatura cero fisiológica durante estos periodos prolongados de recesos, lo que potencialmente puede afectar el desarrollo embrionario. Por tal motivo, es importante evaluar los periodos extensivos de receso en un contexto ecológico e identificar su posible efecto en la aptitud. Con este objetivo, utilizamos data-loggers iButton para monitorear la conducta de incubación de hembras de Cyanistes caeruleus y Parus major durante dos épocas reproductivas en España central. Clasificamos como recesos extendidos en la incubación, si estos eran cuatro veces mayores que el periodo promedio de recesos en cada especie. Los periodos extensivos de receso ocurrieron con mayor frecuencia en el 2012, cuando las hembras mostraron una peor condición corporal. Las hembras de Cyanistes caeruleus tuvieron periodos de receso en la incubación más extendidos que las hembras de Parus major y en ambas especies los periodos de receso extendido ocurrieron al principio de la temporada de reproducción. Tanto el periodo de atención del nido como el promedio mínimo de la temperatura dentro del nido disminuyó cuando se presentó por lo menos un periodo extendido de receso. El periodo de incubación fue, en promedio, cuatro días más largo en nidos en los que las hembras tuvieron por lo menos un receso extendido, incrementando potencialmente el riesgo de depredación y resultando en una calidad más baja de los polluelos. En general, nuestros resultados sugieren que los periodos extendidos de receso, pueden ser más comunes en aves cantoras que lo que se pensaba con anterioridad, y que, dado su efecto en la temperatura de los huevos y atención del nido, pudiera acarrear costos asociados con la aptitud reproductiva.

Key words: embryo development, energy constraints, iButton, temperature, trade-off

\footnotetext{
${ }^{5}$ Corresponding author. Email: jbuenoenciso@ gmail.com
}

Bird embryos are ectothermic and depend on heat provided by their parents to maintain 
the optimal developmental temperature (White and Kinney 1974). However, during incubation, single-sex, intermittent incubators must leave nests regularly for feeding and self-maintenance, although, in some species, one member of a pair can feed the other while incubating (Lack 1940). Most songbirds exhibit this incubation strategy, where only one parent (usually the female) incubates, and, therefore, egg temperatures fluctuate as females depart from and return to nests (Deeming 2002). In most environments, ambient temperatures during the breeding season are outside the optimal range for embryonic development (Camfield and Martin 2009) so incubating females should attempt to maintain embryonic temperatures within this range (Haftorn 1988). However, on-bout duration may be constrained by the energy budgets of females (Ardia et al. 2009). Consequently, uniparental, intermittent incubation patterns reflect a trade-off between self-maintenance and the temperature requirements of embryos (Cooper and Voss 2013).

Extended incubation recesses appear to be part of the normal incubation strategy of some species of birds, e.g., seabirds and several species of landbirds (Boersma and Wheelwright 1979, Wang and Beissinger 2009, Blight et al. 2010, Jia et al. 2010). Among passerines, this behavior appears related to parental energy constraints, usually resulting from prolonged periods of inclement weather (Haftorn 1988, MacDonald et al. 2013). During extended incubation recesses at temperate climates, egg temperatures potentially fall below the physiological zero temperature (PZT), which is assumed to be $26^{\circ} \mathrm{C}$ (Lundy 1969, Nord and Williams 2015).

The potential fitness costs to developing embryos of extended recesses and the resulting periods of hypothermia are poorly understood (Nord and Williams 2015). The results of some studies suggest that extended recesses do not impair the hatchability of eggs (Morton and Pereyra 1985, Haftorn 1988, Wang and Beissinger 2009), and that passerine embryos are well-adapted to long periods of cooling. However, MacDonald et al. (2013) found that the hatchability of Horned Lark (Eremophila alpestris) eggs in an alpine environment was reduced by $\sim 10 \%$ in clutches that experienced at least one extended recess. Other potential fitness consequences of egg neglect include an increase in the duration of the incubation period, which could occur because embryonic development slows under conditions of hypothermia (Conway and Martin 2000). Longer incubation periods may increase predation risk (Martin 2002, Martin et al. 2007), and also increase energy expenditure by parents and embryos during their development (Eiby and Booth 2009), so that their phenotype can be negatively affected in a number of ways, including locomotor performance, immune responses, and body size (DuRant et al. 2013).

We monitored incubation behavior in sympatric populations of Blue Tits (Cyanistes caeruleus) and Great Tits (Parus major), two species with female-only, intermittent incubation, in a Mediterranean area in central Spain. Both species used nest boxes that create a buffered thermal micro-environment for incubation. Our objective was to determine the prevalence of extended recesses and their potential fitness consequences. We predicted that extended recesses would be more prevalent in colder years because of the extra costs that low temperatures impose on incubating females (Haftorn and Reinertsen 1985, Nord et al. 2010), and that those clutches where females took extended recesses would experience reduced fitness in the form of longer incubation periods and reduced hatching success (Martin et al. 2007, MacDonald et al. 2013, Nord and Williams 2015).

\section{METHODS}

Our study was conducted in San Pablo de los Montes (39 $\left.32^{\prime} 44^{\prime \prime} \mathrm{N}, \quad 4^{\circ} 19^{\prime} 41^{\prime \prime} \mathrm{W}\right)$, located in a mountainous region in the southern Toledo province (central Spain). Our study area included 10 oak (Quercus pyrenaica) forest patches with a mean altitude of $1400 \mathrm{~m}$ asl. The region has a continental Mediterranean climate, characterized by pronounced summer droughts, an average daily thermal oscillation of $16^{\circ} \mathrm{C}$, and mean annual rainfall of $700-800 \mathrm{~mm}$. In all forest patches, we attached wooden nest boxes $(N=350)$ to oak branches $2-3 \mathrm{~m}$ above the ground and $30 \mathrm{~m}$ apart. At 30-m intervals in three forest patches, we also hung 20 woodcrete nest boxes $(N=60)$ next to the wooden nest boxes at the same height and density. Data on the material, shape, and size of these nest 
boxes can be found in García-Navas et al. (2008).

Data collection. During the 2012 and 2013 breeding seasons (day $1=1$ April), we inspected nest boxes every $2 \mathrm{~d}$ to obtain basic reproductive parameters such as laying date, clutch size, and hatching date. We defined the incubation period as the number of days between the laying of last egg and the first sign of hatching (Martin et al. 2007). We captured adult females with spring traps while they fed their nestlings (8-9 d old). We banded them, weighed them on a portable balance $( \pm 0.01 \mathrm{~g})$, and measured tarsus length with an electronic caliper $( \pm 0.01$ $\mathrm{mm})$. We obtained ambient temperatures from a meteorological station located in the study area, and calculated the average daily ambient temperature from sunrise until sunset for days when incubation behavior was monitored.

We measured incubation patterns using temperature data loggers (DS1922L Thermochron Data Logger iButtons, OnSolution, Baulkham Hills, NSW, Australia) placed among the eggs. We covered iButtons with brown medical tape to reduce their conspicuousness. IButtons were placed in nests between days 6 and 11 of the incubation period, but $85 \%$ of our incubation data for Blue Tits and $76 \%$ for Great Tits were from days 7,8 , and 9. IButtons were placed in nests the day before temperature measurements were made and removed the day after. IButtons were programmed to start recording temperature at 00:01 and finish two hours after sunset on the same day, recording temperatures every $11 \mathrm{sec}$ for an average of $23 \mathrm{hrs}$ in each nest.

Once we retrieved iButtons, we downloaded the temperature recordings using the Eclo Express-Thermo software 2007 (www.ec lo.pt/expressthermo) and used the program Rhythm 1.0 (Cooper and Mills 2005) to select recesses from nest-temperature recordings. We adjusted Rhythm 1.0 to select a recess when nest temperature dropped by at least $2^{\circ} \mathrm{C}$ for at least $2 \mathrm{~min}$. We then used RavenPro 1.5 (Charif et al. 2010) to visually recheck the output and confirm the recesses automatically selected by Rhythm. This allowed us to determine the frequency and duration of each on-bout and recess. We then searched these data for atypical extended recesses that could result in substantial egg cooling and were therefore likely to be ecologically significant for embryos (MacDonald et al. 2013). Extended recesses were defined as those at least four times longer in duration than the mean recess duration of each species during our 2-year study. Therefore, we defined extended recesses as $>40 \mathrm{~min}$ for Blue Tits and $>55 \mathrm{~min}$ for Great Tits. Because we only monitored incubation behavior on $1 \mathrm{~d}$ of the entire incubation period, our estimate of the prevalence of extended recesses is conservative because females could have taken extended recesses on days they were not monitored. Nonetheless, we classified nests where eggs hatched (i.e., not deserted or predated) as either having an extended incubation recess or not, with the understanding that this reflected only those days that we monitored.

Statistical analyses. We compared the average daily ambient temperatures between years using a two-tailed paired Student's $t$-test. We then examined the prevalence of extended incubation recesses between years and species. This was done by creating a Generalized Linear Mixed Model (GLMM) fitted with a binomial distribution where the response variable was the type of incubation pattern $\quad(0=$ no extended recesses, and 1 = extended recesses), the year, species, and nest-box type were fixed factors, and the forest patch was included as a random term. We included nest-box type as a fixed factor (woodcrete vs. wooden) to correct for the possible effects that the different thermal properties of each type might have on female incubation behavior (Bueno-Enciso et al. 2016). In this analysis, we also included the measurement day (calendar date when incubation behavior was recorded), the average daily ambient temperature, and clutch size as covariates. Average daily ambient temperature and clutch size were included because both variables can influence the costs of incubation (Haftorn and Reinertsen 1985, Nord et al. 2010).

To test whether the extended incubation recesses affected either nest attentiveness or average minimum nest temperatures, we created two GLMMs. One was fitted with a binomial distribution where the response variable was a data frame containing two columns: total time spent incubating eggs and 
total time spent off nests by females (nest attentiveness). In the other GLMM, the response variable was the average minimum nest temperature during the day (Amininasab et al. 2016). Estimating nest temperature during incubation is important because only if this temperature is significantly lower for nests where females have extended incubation recesses can there be fitness consequences as a result of those extended recesses (Nord and Williams 2015). Because bird embryos are ectothermic (White and Kinney 1974), thermal conditions experienced during development are highly correlated with the temperature in their immediate environment (Conway and Martin 2000). In both models, the study year, species, nest-box type, and incubation type (extended recesses or not) were included as fixed factors, and the forest patch as the random term. The measurement day, average daily ambient temperature, and clutch size were included as covariates. Due to the bias that measuring incubation behavior at different embryo ages can introduce in the analyses (Cooper and Voss 2013), we also included this variable in the analysis as a covariate. Embryo age was calculated as the number of days between the laying of the last egg in a clutch and the measurement day.

To test whether extended incubation recesses affected the duration of incubation periods or hatching success, we created two more GLMMs with the same fixed factors and random term as the two previous models, and including hatch day and clutch size as covariates. In one model, the response variable was the duration (in days) of the incubation period and, in the other model, the response variable was a data frame containing two columns: the number of eggs that hatched and the number that did not hatch. This last model was fitted with a binomial distribution. Because species that exhibit single-sex intermittent incubation appear to perform extended recesses due to energetic constraints (Haftorn 1988, MacDonald et al. 2013), we performed another GLMM with female body condition, estimated using the scaled mass index (Peig and Green 2009), as the response variable. In this model, we included study year, nest-box type, and species as fixed factors, the forest patch as the random term, and hatch day and clutch size as covariates.
The incubation behavior of eight female Blue Tits and six female Great Tits was monitored during both years of our study. We conducted our analyses both with and without these duplicated females and the results did not change. Therefore, we treated each female as independent (MacDonald et al. 2013). All models are described in Supplemental Table $S 1$ and were fitted with a Gaussian distribution unless otherwise stated. Graphs of residuals were used to visually assess assumptions of parametric testing (Zuur et al. 2009). The interaction between 'species' and 'incubation type (extended recess or not)' was initially included in all models and subsequently eliminated if it was not significant. All analyses were performed in $\mathrm{R}$ ( $\mathrm{R}$ Core Team 2014) with the 'Ime4' package (Bates et al. 2015). For non-parametric distributions, the Wald chi-square statistic $\left(\chi^{2}\right)$ from the 'car' package (Fox and Weisberg 2011) is provided. Values are provided as means \pm SE.

\section{RESULTS}

Average daily ambient temperature differed between years (Students $t$-test, $t=4.8$, $P<0.001)$, with the mean temperature lower in $2013\left(16.5 \pm 0.4^{\circ} \mathrm{C}\right)$ than 2012 $\left(19.8 \pm 0.5^{\circ} \mathrm{C}\right)$. During our study, we recorded the incubation activity of 157 female Blue Tits and 117 female Great Tits, with 4078 and 2276 recesses by female Blue and Great tits, respectively. In all cases, females spent the prior night on nests incubating eggs. Female Blue Tits $(N=21$ nests $)$ took 29 extended recesses $(0.7 \%$ of all recesses $)$, and female Great Tits ( $N=8$ nests) took nine $(0.4 \%$ of all recesses; Table 1$)$. Most females had just one extended recess (Table 1).

Extended recesses were more frequent in $2012(15.2 \pm 2.9 \%$ of nests) than in 2013 $(4.9 \pm 2.0 \%$ of nests), and in Blue Tits $(13.4 \pm 2.7 \%$ of nests) than Great Tits $(6.8 \pm 2.3 \%$ of nests, Table 2$)$. Extended recesses occurred more frequently at the beginning of the breeding season. Neither ambient temperature nor clutch size affected the prevalence of extended incubation recesses (Table 2).

Nest attentiveness was significantly lower in 2012 than in 2013 for both Great Tits (2012: 
Table 1. Number of incubation periods and recesses recorded for Blue Tits and Great Tits during the 2012 and 2013 breeding seasons in San Pablo de los Montes (Toledo, central Spain). ER = extended recess.

\begin{tabular}{lcc}
\hline & \multicolumn{2}{c}{ Blue Tits } \\
\cline { 2 - 3 } & 2012 & 2013 \\
\hline Number of incubation periods & 78 & 79 \\
Number of periods with ER & 16 & 5 \\
ER prevalence & $2.9 \%$ & $8.8 \%$ \\
Number of recesses & 1992 & 2086 \\
Number of ER & 22 & 7 \\
ER prevalence & $1.05 \%$ & $0.34 \%$ \\
Mean recess duration (min) \pm SE & $9.1 \pm 0.1$ & $8.5 \pm 0.1$ \\
Mean ER duration (min) \pm SE & $216.1 \pm 28.8$ & $94.5 \pm 29.4$ \\
\hline & & Great Tits \\
& & \\
& 2012 & 2013 \\
\hline Number of incubation periods & 73 & 1 \\
Number of periods with ER & 7 & $2.3 \%$ \\
ER prevalence & $8.1 \%$ & 1000 \\
Number of recesses & 1276 & $0.10 \%$ \\
Number of ER & 8 & $11.5 \pm 0.2$ \\
ER prevalence & $0.55 \%$ & 141.3 \\
Mean recess duration (min) \pm SE & $13.7 \pm 0.2$ & \\
Mean ER duration (min) \pm SE & $211.0 \pm 66.7$ &
\end{tabular}

$66.9 \pm 1.3 \%, 2013: 70.6 \pm 1.0 \%)$ and Blue Tits (2012: $63.2 \pm 1.5 \%, 2013: 70.4 \pm$ $0.8 \%)$, in woodcrete nest boxes than in wooden nest boxes (Great Tits: woodcrete $=$ $64.2 \pm 2.1 \%$, wooden $=70.2 \pm 0.7 \%$; Blue Tits: woodcrete $=63.8 \pm 2.2 \%$, wooden $=$ $67.6 \pm 1.0 \%)$, and in nests with extended recesses (ER) than in nests with no extended recesses (NER; Great Tits: ER $=47.1$ $\pm 7.4 \%$, NER $=69.8 \pm 0.5 \%$; Blue Tits: $\mathrm{ER}=48.2 \pm 3.3 \%, \mathrm{NER}=69.7 \pm 0.6 \%$; Table 2). Nest attentiveness also differed between species, with Great Tits (68.5 \pm $0.9 \%)$ more attentive than Blue Tits (66.8 $\pm 0.9 \%$; Table 2). All covariates in this model significantly and positively affected nest attentiveness of both species, i.e., nest attentiveness increased as the breeding season progressed and with increasing age of embryos, higher average daily ambient temperatures, and larger clutch sizes (Table 2).

Minimum nest temperatures were lower in $2012\left(25.8 \pm 0.6^{\circ} \mathrm{C}\right)$ than $2013(26.5 \pm$ $\left.0.4^{\circ} \mathrm{C}\right)$, in wooden nest boxes $\left(26.0 \pm 0.4^{\circ} \mathrm{C}\right)$ than woodcrete boxes $\left(26.4 \pm 0.8^{\circ} \mathrm{C}\right)$, and for nests with extended recesses than nests with no extended recesses (Great Tits: $\mathrm{ER}=19.1 \pm 3.5^{\circ} \mathrm{C}, \mathrm{NER}=27.6 \pm 0.3^{\circ} \mathrm{C}$; Blue Tits: $\mathrm{ER}=15.0 \pm 2.0^{\circ} \mathrm{C}, \mathrm{NER}=27.1$ $\pm 0.4^{\circ} \mathrm{C}$; Table 2). Additionally, average daily ambient temperature and clutch size exhibited a positive relationship with minimum nest temperature (Table 2).

The duration of incubation periods was significantly longer for clutches with at least one extended recess for both Great Tits $(\mathrm{ER}=17.13 \pm 1.37 \mathrm{~d}, \quad \mathrm{NER}=13.54 \pm$ $0.29 \mathrm{~d})$ and Blue Tits $(\mathrm{ER}=17.1 \pm 0.7 \mathrm{~d}$, NER $=14.1 \pm 0.2 \mathrm{~d}$; Table 3). Additionally, the duration of incubation periods was negatively related to hatching date (Table 3). Hatching success was higher in 2013 $(81.7 \pm 1.7 \%)$ than in $2012(78.4 \pm 1.7 \%)$ and was higher for Great Tits $(83.6 \pm 1.7 \%)$ than Blue Tits $(76.9 \pm 1.7 \%$; Table 3$)$. Female body condition was worse in 2012 than in 2013 for both Great Tits $(2012=0.14 \pm 0.17, \quad 2013=0.52 \pm 0.20)$ and Blue Tits $(2012=-0.44 \pm 0.18$, $2013=-0.01 \pm 0.14)$, and was worse for 


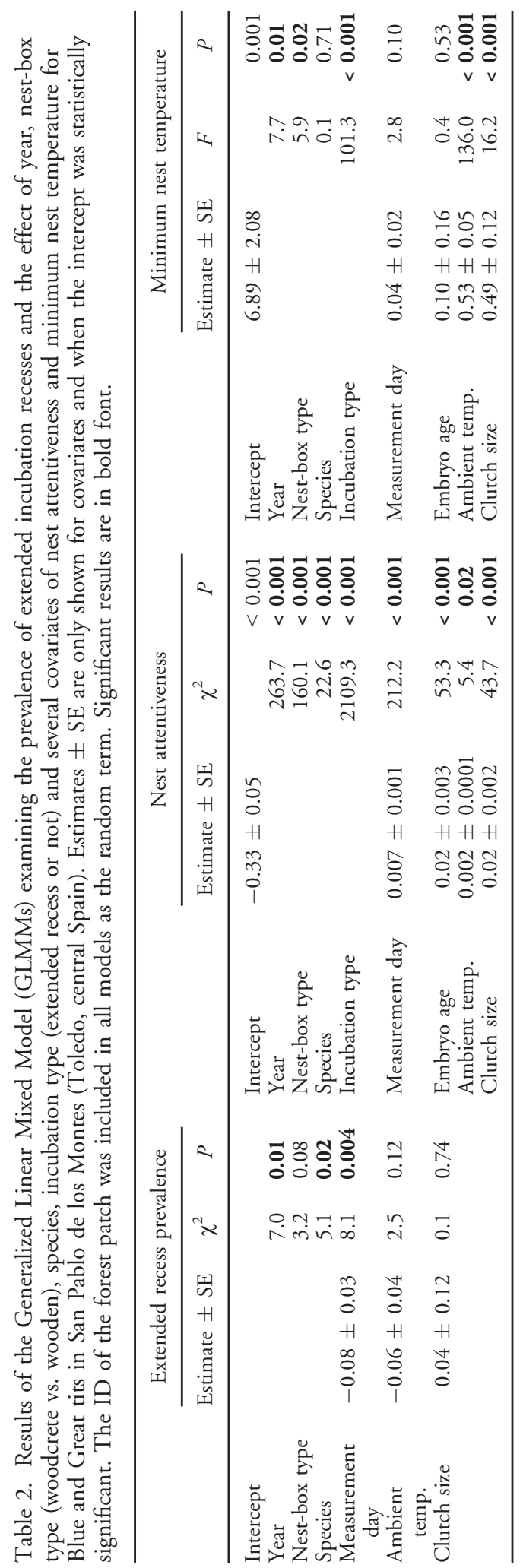




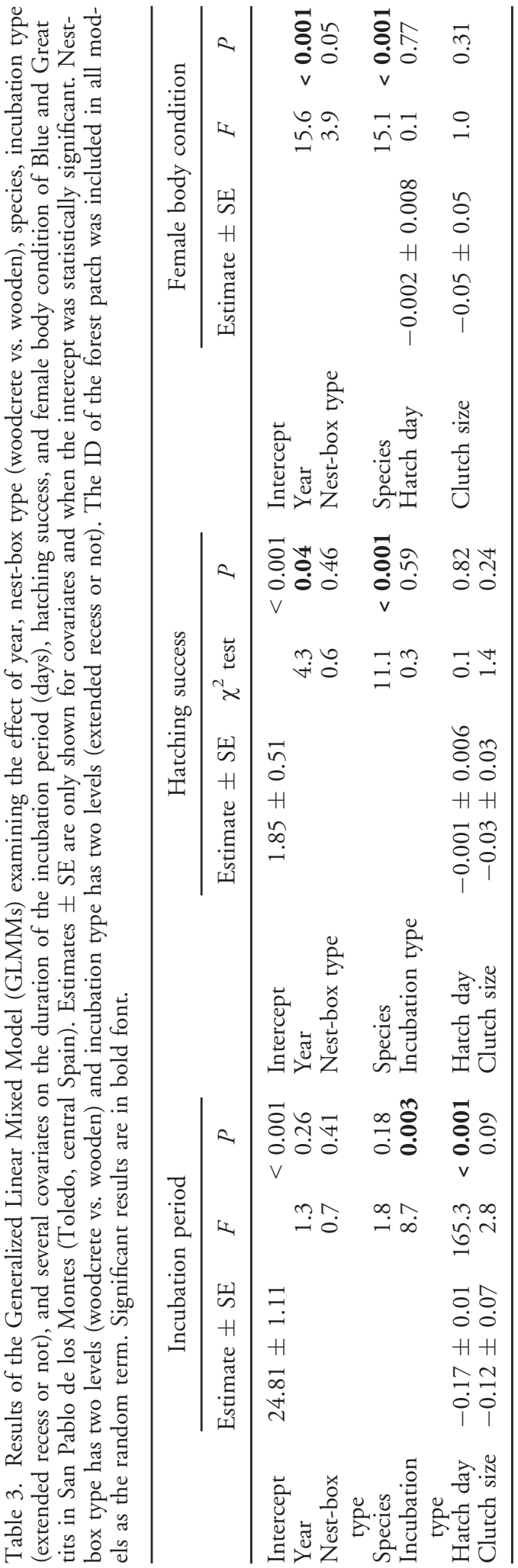


Blue Tits $(-0.19 \pm 0.11)$ than Great Tits $(0.29 \pm 0.13)$. No other independent variable affected female body condition (Table 3).

\section{DISCUSSION}

Extended recesses accounted for $<1 \%$ of the total number of recesses performed by female Great and Blue tits, a value similar to that reported for an alpine population of Horned Larks (MacDonald et al. 2013). The low prevalence of this behavior may explain why it has often been overlooked. Nonetheless, we observed reduced attentiveness and lower minimum nest temperatures in nests where females took extended recesses, suggesting the importance of considering this behavior in an ecological context. We found that extended incubation recesses were more prevalent in 2012 than in 2013 for both species, and that Blue Tits exhibited this behavior more than Great Tits. Although 2012 was significantly warmer than 2013, which may have reduced the costs of incubation (Nord et al. 2010), the body condition of females of both species was significantly worse in 2012 . Limited energy reserves may have made it more difficult to cope with the costs of incubation, which may have accounted for the greater number of extended incubation recesses in 2012 and for Blue Tits, the species with poorer body condition. Similarly, Wiebe and Martin (1997) found that the frequency of extended incubation recesses by female White-tailed Ptarmigan (Lagopus leucura) was inversely related to body condition. Extended recesses occurred more frequently at the beginning of breeding season in our study, possibly because temperatures were lower and nights longer earlier in the season, factors that increase the energetic costs of incubation (Haftorn and Reinertsen 1985, Nord et al. 2010, Ricklefs and Brawn 2013, Álvarez and Barba 2014).

We found that even one extended recess during incubation reduced overall nest attentiveness. Nest attentiveness is determined by females based on their own energy reserves, rather than on egg temperature (Chaurand and Weimerskirch 1994, Reid et al. 1999, Ardía et al. 2009), perhaps explaining why nest attentiveness was lower in 2012 than 2013 and for Blue Tits than Great Tits. Nest attentiveness also differed between nest-box types, with lower attentiveness in woodcrete nest boxes. The average warmer microclimate in woodcrete nest boxes may allow females to allocate more energy to selfmaintenance (Chalfoun and Martin 2007, Bueno-Enciso et al. 2016). However, contrary to this pattern, as ambient temperatures increased, nest attentiveness increased. This positive relationship between average daily ambient temperature and nest attentiveness appeared to be driven by the greater prevalence of extended recesses early in the breeding season when ambient temperatures were lower.

Nest attentiveness also increased during the breeding season, perhaps due to an increase in food availability. Females were also more attentive with the increasing age of embryos, probably because the temperature of embryos needs to be more tightly regulated as embryos develop (Cooper and Voss 2013). Clutch size also positively affected nest attentiveness, which could be related to female quality, i.e., higher-quality females were able to lay more eggs and be more attentive. In addition, however, larger clutches cool more slowly than smaller ones (Boulton and Cassey 2012). Thus, females with larger clutches might have conserved energy because of a reduced need to rewarm clutches after recesses, and used these energy savings to increase their nest attentiveness.

Extended recesses could have fitness consequences for young if the mean temperature experienced by embryos during the incubation period is lower when incubating parents take extended recesses (Nord and Williams 2015). We found that the minimum nest temperature recorded for nests where females had extended recesses was well below the PZT, whereas the minimum nest temperature for nests where there were no extended recesses was not. This suggests that, during extended recesses, egg temperatures can drop below the PZT, the temperature below which embryonic development is suspended (White and Kinney 1974). In addition, although we cannot be certain that females that did not take extended recesses on the day they were monitored did not take an extended recess on days when they were not monitored, nests in our study with at least one extended recess had incubation periods that averaged $4 \mathrm{~d}$ 
longer. Carter et al. (2014) reported similar results for Wood Ducks (Aix sponsa), and these longer incubation periods could be related to the suboptimal thermal conditions experienced by the embryos due to the extended recesses. Longer incubation periods may have fitness costs associated with an increase in the risk of predation (Martin 2002, Martin et al. 2007) and with increased energy expenditure by embryos during development, which could have a negative impact on nestlings (Hepp et al. 2006, Eiby and Booth 2009, DuRant et al. 2013).

Hatching success in our study did not differ between nests with and without extended incubation recesses. In contrast, MacDonald et al. (2013) reported a reduction in hatching success of $10 \%$ in clutches that experienced at least one extended recess. Our result could be due to the conservative nature of our classification system, or to females with at least one extended recess subsequently compensating by providing optimal conditions during the remainder of the incubation period (Carter et al. 2014). Other investigators have also reported no effect of prolonged periods of hypothermia on hatching success (Haftorn 1988, Wang and Beissinger 2009).

In conclusion, our results provide additional support for the idea that extended recesses may be more common among songbirds than previously thought. Although such recesses may be infrequent, their effects on egg temperatures and attentiveness make them potentially ecologically significant.

\section{ACKNOWLEDGMENTS}

We thank the council of San Pablo de los Montes (Toledo, Spain) for allowing us to work there and for the facilities provided during field work. Funding was provided by MINECO (CGL2013-48001-C2-1-P, CGL2010-21933-C02-01) and the Junta de Comunidades de Castilla-La Mancha and the European Social Fund (POIC10-0269-7632). ESF and JBE were both supported by a doctoral scholarship from the Junta de Comunidades de Castilla-La Mancha-European Social Fund and RB benefitted from the JCCM-FSE 2007/2013 postdoctoral programme and from a "Juan de la Cierva" post-doctoral contract (JCI-2011-10945). We also thank an anonymous reviewer for valuable comments on our manuscript. All applicable international, national, and/or institutional guidelines for the care and use of animals were followed.

\section{LITERATURE CITED}

Álvarez, E., AND E. Barba. 2014. Within and between population variations of incubation rhythm of Great Tits Parus major. Behaviour 151: 1827-1845.

Amininasab, S. M., S. A. Kingma, M. Birker, H. Hildenbrant, AND J. Komdeur. 2016. The effect of ambient temperature, habitat quality and individual age on incubation behaviour and incubation feeding in a socially monogamous songbird. Behavioral Ecology and Sociobiology 70: 1591-1600.

Ardia, D. R., J. H. Pérez, E. K. Chad, M. A. Voss, And E. D. Clotfelter. 2009. Temperature and life history: experimental heating leads female Tree Swallows to modulate egg temperature and incubation behavior. Journal of Animal Ecology 78: 4-13.

Bates, D., M. Maechler, B. Bolker, And S. WALKER. 2015. Fitting Linear Mixed-Effects Models Using lme4. Journal of Statistical Software 67: 1-48.

Blight, L. K., D. F. Bertram, T. D. Williams, and L. COWEN. 2010. Interannual variation in egg neglect and incubation routine of Rhinoceros Auklets Cerorhinca monocerata during the 19981999 el Niño / la Niña events. Marine Ornithology 38: 11-15.

Boersma, P. D., AND N. T. WheElWright. 1979. Egg neglect in the Procellariiformes: reproductive adaptations in the Fork-tailed Storm-Petrel. Condor 81: 157-165.

Boulton, R. L., AND P. CAssey. 2012. How avian incubation behaviour influences egg surface temperatures: relationships with egg position, development and clutch size. Journal of Avian Biology 43: 289-296.

Bueno-Enciso, J., E. S. Ferrer, R. Barrientos, and J. J. SANZ. 2016. Effect of the nestbox type on the breeding performance of two secondary holenesting passerines. Journal of Ornithology 157: 759-772.

Camfield, A. F., And K. Martin. 2009. The influence of ambient temperature on Horned Lark incubation behaviour in an alpine environment. Behaviour 146: 1615-1633.

Carter, A. W., W. A. Hopkins, I. T. MoOre, AND S. E. Durant. 2014. Influence of incubation recess patterns on incubation period and hatchling traits in Wood Ducks Aix sponsa. Journal of Avian Biology 45: 273-279.

Chalfoun, A. D., AND T. E. Martin. 2007. Latitudinal variation in avian incubation attentiveness and a test of the food limitation hypothesis. Animal Behaviour 73: 579-585.

Charif, R. A., L. M. Strickman, and A. M. WaAck. 2010. Raven Pro 1.5 user's manual. Cornell Lab of Ornithology, Ithaca, NY.

Chaurand, C., AND H. WeIMERSKIrCH. 1994. Incubation routine, body mass regulation and egg neglect in the Blue Petrel Halobaena caerulea. Ibis 136: 285-290.

Conway, C. J., And T. E. Martin. 2000. Effects of ambient temperatures on avian incubation behavior. Behavioral Ecology 11: 178-188. 
CoOper, C. B., AND H. Mills. 2005. New software for quantifying incubation behavior from timeseries recordings. Journal of Field Ornithology 76: 352-356.

, AND M. A. Voss. 2013. Avian incubation patterns reflect temporal changes in developing clutches. PLoS ONE 8: e65521.

DeEming, D. C. 2002. Behavior patterns during incubation. In: Avian incubation: behavior, environment, and evolution (D. C. Deeming, ed.), pp. 63-87. Oxford University Press, New York, NY.

DuRant, S. E., W. A. Hopkins, G. R. Hepp, and J. R. WALTERS. 2013. Ecological, evolutionary, and conservation implications of incubation temperature dependent phenotypes in birds. Biological Reviews 88: 499-509.

Eiby, Y. A., AND D. T. BoOTH. 2009. The effects of incubation temperature on the morphology and composition of Australian Brush-Turkey (Alectura lathami) chicks. Journal of Comparative Physiology B 179: 875-882.

Fox, J., AND S. WeisberG. 2011. An R companion to applied regression, 2nd ed. Sage, Thousand Oaks, CA.

García-Navas, V., L. Arroyo, J. J. Sanz, and M. DíAZ. 2008. Effect of nestbox type on occupancy and breeding biology of Tree Sparrows Passer montanus in central Spain. Ibis 150: 356-364.

HAFTORN, S. 1988. Incubating female passerines do not let the egg temperature fall below the 'physiological zero temperature' during their absences from the nest. Ornis Scandinavica 19: 97-110.

—, AND R. E. Reinertsen. 1985. The effect of temperature and clutch size on the energetic costs of incubation in a free-living Blue Tit (Parus caeruleus). Auk 102: 470-478.

Hepp, G. R., R. A. Kennamer, and M. H. Johnson. 2006. Maternal effects in Wood Ducks: incubation temperature influences incubation period and neonate phenotype. Functional Ecology 20: 307-314.

JiA, C. X., Y. H. Sun, And J. E. Swenson. 2010. Unusual incubation behavior and embryonic tolerance of hypothermia by the Blood Pheasant (Ithaginis cruentus). Auk 127: 926-931.

LACK, D. 1940. Courtship feeding in birds. Auk 57: $169-178$.

LunDY, H. 1969. A review of the effects of temperature, humidity, turning and gaseous environment in the incubator on the hatchability of the hen's egg. In: The fertility and hatchability of the hen's egg (T. C. Carter and B. M. Freeman, eds.), pp. 143-176. Oliver and Boyd, Edinburgh, UK.

MacDonald, E. C., A. F. Campield, J. E. JANKOWSKI, AND K. MARTIN. 2013. Extended incubation recesses by alpine-breeding Horned Larks: a strategy for dealing with inclement weather? Journal of Field Ornithology 84: 58-68.

Martin, T. E. 2002. A new view for avian life history evolution tested on an incubation paradox. Proceedings of the Royal Society B 269: 309-316.
S. K. Auer, R. D. Bassar, A. M. Niklison, AND P. LLOYD. 2007. Geographic variation in avian incubation periods and parental influences on embryonic temperature. Evolution 61: 25582569.

Morton, M. L., And M. E. Pereyra. 1985. The regulation of egg temperatures and attentiveness patterns in the Dusky Flycatcher (Empidonax oberholseri). Auk 102: 25-37.

Nord, A., M. I. SANDEll, AND J. A. Nilsson. 2010. Female Zebra Finches compromise clutch temperature in energetically demanding incubation conditions. Functional Ecology 24: 1031-1036.

-, AND J. B. Williams. 2015. The energetic costs of incubation. In: Nests, eggs and incubation (D. C. Deeming and S. J. Reynolds, eds.), pp. 142-151. Oxford University Press, Oxford, UK.

Peig, J., AND A. J. Green. 2009. New perspectives for estimating body condition from mass/length data: the scaled mass index as an alternative method. Oikos 118: 1883-1891.

R CORE TEAM [online]. 2014. R: A language and environment for statistical computing. $\mathrm{R}$ Foundation for Statistical Computing, Vienna, Austria <http://www.R-project.org/>.

Reid, J. M., P. Monaghan, and G. D. Ruxton. 1999. The effect of clutch cooling on starling, Sturnus vulgaris, incubation strategy. Animal Behaviour 58: 1161-1167.

Ricklefs, R. E., AND J. BRAWN. 2013. Nest attentiveness in several Neotropical suboscine passerine birds with long incubation periods. Journal of Ornithology 154: 145-154.

WANG, J. M., AND S. R. BeISSINGER. 2009. Variation in the onset of incubation and its influence on avian hatching success and asynchrony. Animal Behaviour 78: 601-613.

White, F. N., AND J. L. Kinney. 1974. Avian incubation. Science 189: 107-115.

Wiebe, K. L., AND K. Martin. 1997. Effects of predation, body condition and temperature on incubation rhythms of White-tailed Ptarmigan Lagopus leucurus. Wildlife Biology 3: 219-227.

Zuur, A. F., E. N. Ieno, N. J. Walker, A. A. Saveliev, and G. M. Smith. 2009. Mixed effects models and extensions in ecology with R. Springer, New York, NY.

\section{SUPPORTING INFORMATION}

Additional Supporting Information may be found in the online version of this article at the publisher's website.

Table S1. Description of the General Linear Mixed Models (GLMM) employed in this study. 